Revista Bioética

\title{
PESQUISA
}

\section{Conhecimento e prática universitária no uso de imagens de pacientes}

Isabela Cristina de Miranda Gonçalves ${ }^{1}$, Jacqueline de Almeida Gonçalves Sachett ${ }^{2}$, Waldeyde O. Magalhães dos Santos ${ }^{3}$, Shirley Maria de Araújo Passos ${ }^{4}$

1. Departamento de Enfermagem, Escola Superior de Ciências da Saúde, Universidade do Estado do Amazonas, Manaus/AM, Brasil. 2. Programa de Pós-Graduação em Doenças Tropicais e Infecciosas, Escola Superior de Ciências da Saúde, Universidade do Estado do Amazonas, Manaus/AM, Brasil. 3. Centro de Pesquisa e Desenvolvimento, Escola Superior de Ciências da Saúde, Universidade do Estado do Amazonas, Manaus/AM, Brasil. 4. Centro de Especialidades Odontológicas, Escola Superior de Ciências da Saúde, Universidade do Estado do Amazonas, Manaus/AM, Brasil.

\section{Resumo}

O uso de tecnologias da informação e comunicação na área da saúde tem crescido paralelamente ao avanço tecnológico. Por meio de pesquisa exploratória, descritiva, transversal e de abordagem quantitativa, objetivou-se identificar o conhecimento e a prática de discentes e docentes de universidade pública estadual sobre captação e reprodução de imagens de pacientes atendidos durante a prática acadêmica. Participaram do estudo 200 discentes matriculados nos cursos de odontologia, medicina e enfermagem, assim como 33 docentes que ministram alguma disciplina do ciclo profissional em qualquer dos referidos cursos. A pesquisa revelou preocupação com aspectos éticos e legais referentes a captura, armazenamento e disseminação de imagens clínicas de pacientes pelos profissionais e estudantes da saúde durante o processo de ensino e aprendizagem.

Palavras-chave: Ética. Legislação. Privacidade. Fotografia.

\section{Resumen}

\section{Conocimiento y práctica universitaria en el uso de imágenes de pacientes}

El uso de tecnologías de la información y la comunicación en el área de la salud viene creciendo en paralelo al avance de la tecnología. Por medio de una investigación exploratoria, descriptiva, transversal y de abordaje cuantitativo, se pretendió identificar el conocimiento y la práctica de discentes y docentes de una universidad pública sobre la captación y la reproducción de imágenes de pacientes atendidos durante la práctica académica. Participaron en el estudio 200 discentes matriculados en las carreras de odontología, medicina y enfermería, así como 33 docentes que impartían alguna asignatura del ciclo profesional en cualquiera de dichas carreras. La investigación reveló una preocupación de los profesionales y estudiantes con los aspectos éticos y legales referentes a la captación, almacenamiento y divulgación de imágenes clínicas durante el proceso de enseñanza y aprendizaje. Palabras clave: Ética. Legislación. Privacidad. Fotografía.

\section{Abstract}

\section{Knowledge of the use of patient images at the university}

The use of information and communication technologies in the healthcare area has grown with technological advancements. Through an exploratory, descriptive, cross-sectional and quantitative approach, this study aimed to identify the knowledge and practice of students and professors of a public state university regarding the capture and reproduction of images from patients who have been attended by them. The research had the participation of 200 students enrolled in the dentistry, medicine and nursing courses, as well as 33 professors of these courses. The results show that they care about the ethical and legal aspects underlying the capture, handling, storage and dissemination of clinical images during the teaching and learning process.

Keywords: Ethics. Legislation. Privacy. Photograph. 
As tecnologias de informação e comunicação na área da saúde têm avançado exponencialmente, instigando a discussão acerca de seu uso ético. Como a atenção à saúde é atualmente multiprofissional, com informações sendo compartilhadas por diversas pessoas, tem-se preocupado em garantir a segurança dos dados dos pacientes, sobretudo quando se trata de imagens ${ }^{1}$.

Muitas tecnologias de compartilhamento de imagens, como redes sociais, têm surgido nos últimos anos. Esse advento acarretou entraves bioéticos na saúde quanto à publicação de imagens, bem como a condutas, procedimentos e técnicas que expõem pacientes. Nesse enredo, a Convenção sobre os Direitos do Homem e a Biomedicina, firmada em 1997, já visando proteger dados, versa sobre consentimento como forma de resguardar a integridade do sujeito ${ }^{2}$.

O artigo 60 da Declaração Universal sobre Bioética e Direitos Humanos ${ }^{3}$ determina que a autonomia individual deve ser preservada, seja em condutas profiláticas, diagnósticas, terapêuticas ou em investigações. Por conseguinte, a decisão de líderes ou representantes legais de grupos ou comunidades não sobrepõe a opinião individual, podendo o paciente retirar seu consentimento por qualquer motivo e em qualquer momento, sem qualquer prejuízo ou desvantagem ${ }^{3}$.

O uso de dados do paciente em pesquisas no Brasil é regulamentado pelo Conselho Nacional de Saúde (CNS) ${ }^{4}$, o qual reitera os preceitos da Declaração ${ }^{3}$, estabelecendo a obrigatoriedade do termo de consentimento livre e esclarecido (TCLE). A assinatura desse documento visa resguardar tanto o participante quanto o pesquisador de qualquer entrave bioético e, dessa forma, o responsável pelo estudo pode veicular imagens do paciente para fins científicos, contanto que assim expresso no termo.

No Brasil, a Resolução CNS 510/2016 ${ }^{4}$ estabelece normas e diretrizes para pesquisas envolvendo seres humanos e destaca que o consentimento (de participantes capazes de consentir) e o assentimento (dos incapazes de fazê-lo) são fundamentais. Contudo, esse diploma se refere apenas a etapas de estudo, não ao uso clínico-assistencial de fotografias por profissionais para divulgar ou acompanhar procedimentos.

Ainda sobre o processo de consentimento livre e esclarecido abordado na Resolução CNS 510/20164, o direito de autorizar o uso de imagens de pacientes mortos ou ausentes recai sobre cônjuge, ascendentes ou descendentes, conforme o Código Civil brasileiro ${ }^{5}$.
No caso de crianças, adolescentes, pessoas com transtorno ou doença mental ou que tenham sua capacidade de decisão afetada, o profissional da saúde precisa obter consentimento do responsável legal, e o participante deve assentir, se possível, com base em prévia explicação adequada à sua capacidade de entendimento.

Também o princípio de respeito à privacidade é claro em diversos dispositivos éticos e legais nacionais e internacionais. Porém, algumas pesquisas, como a de Martorell, Nascimento e Garrafa ${ }^{6}$, revelam que os profissionais desconhecem esse princípio e publicam imagens que o colocam em risco.

Dado o exposto, a abordagem conceitual nesta pesquisa presume que as competências são desenvolvidas assimilando conhecimentos e integrando habilidades e atitudes no trabalho prático, possibilitando decisões fundamentadas. Portanto, o conceito de competência se sustenta em três dimensões: conhecimento, atitude e prática ${ }^{7,8}$.

A primeira dimensão implica recordar eventos específicos ou conseguir aplicá-los na resolução de problemas, bem como emitir conceitos compreendidos diante de tais acontecimentos. De forma geral, é o saber acerca de tudo o que se aprende na vida, nas escolas e universidades, no ambiente de trabalho, no relacionamento interpessoal e ainda nos livros. Já a prática diz respeito a decidir executar uma ação. Esse processo envolve, por exemplo, os domínios psicomotor, afetivo e cognitivo em dimensão social. É o saber fazer, quando se usa o conhecimento nas atividades da vida diária ${ }^{7,8}$

O cuidado para com o paciente é individualizado, multidisciplinar e busca respeitar sua autonomia e singularidade, mas percebem-se fragilidades e distinções nos preceitos éticos e legais que regem diferentes profissões da saúde. Diante do exposto, este estudo teve como objetivo identificar o conhecimento e a prática de discentes e docentes de universidade pública estadual sobre captação e reprodução de imagens de pacientes atendidos durante a prática acadêmica.

\section{Método}

Trata-se de estudo transversal, quantitativo e de caráter descritivo, realizado a partir de dados primários coletados via questionário autoaplicável. Foram incluídos acadêmicos maiores de 18 anos e regularmente matriculados em disciplinas do ciclo profissional dos cursos de odontologia, medicina e enfermagem da Escola Superior de Ciências da 
Saúde no município de Manaus/AM. Quanto aos docentes, participaram os que estivessem em pleno exercício da função e que ministrassem alguma disciplina do ciclo profissional dos referidos cursos. Foram excluídos da pesquisa os discentes e docentes que não atenderam a qualquer um dos critérios de inclusão, assim como os de etnia indígena, pois estudos envolvendo povos indígenas demandariam maior tempo de execução, conforme dispõe a Resolução CNS 304/2000.

A partir do quantitativo de alunos matriculados no primeiro semestre de 2019 , estimou-se o número de discentes no ciclo profissional por curso. Para o cálculo amostral utilizou-se o software Open Epi, frequência antecipada de $50 \%$ e intervalo de confiança de $95 \%$. Empregou-se questionário estruturado e autoaplicável, abrangendo dados sociodemográficos dos discentes (idade, sexo, curso de formação, tempo de graduação e procedência) e dos docentes (idade, sexo, categoria profissional, tempo de formação e formação complementar), além de perguntas sobre o tema estudado. Tomou-se como referência o roteiro utilizado na pesquisa de Caires e colaboradores ${ }^{10}$.

Os dados foram coletados em abril de 2019 por meio de formulário construído no Google Forms e aplicado ao público-alvo em abordagem individual, utilizando tablets nas dependências da Escola de Saúde. Os candidatos foram orientados quanto aos objetivos da pesquisa e, ao decidir participar, acessaram o formulário por intermédio de seu e-mail institucional. As informações obtidas foram apresentadas por meio de análise descritiva, englobando todos os participantes e estratificando-os em discentes e docentes. A significância estatística foi avaliada pelo intervalo de confiança e, quando necessário, valor de $p$ de $5 \%$.

\section{Resultados}

Foram abordados 233 indivíduos, e todos concordaram em participar da pesquisa mediante assinatura do TCLE. Destes, $200(85,8 \%)$ eram discentes e $33(14,2 \%)$ docentes. A Tabela 1 apresenta os dados coletados sobre os alunos participantes, dentre os quais se nota predomínio do sexo feminino $(54,5 \%)$, na faixa etária de 18 a 25 anos (83\%). Observa-se, ainda, equilíbrio quanto à procedência de estudantes da capital e do interior. Já a Tabela 2 caracteriza os docentes participantes, dos quais $75,8 \%$ são do sexo feminino, $69,7 \%$ são doutores e $45,5 \%$ se graduaram entre 10 e 20 anos atrás.
Tabela 1. Caracterização dos acadêmicos da Escola Superior de Ciências da Saúde participantes da pesquisa (Manaus/AM, 2019)

\begin{tabular}{|c|c|c|}
\hline Características & $n$ & $\%$ \\
\hline \multicolumn{3}{|l|}{ Sexo } \\
\hline Masculino & 91 & 45,5 \\
\hline Feminino & 109 & 54,5 \\
\hline \multicolumn{3}{|l|}{ Faixa etária } \\
\hline 18 a 25 anos & 166 & 83,0 \\
\hline 26 a 32 anos & 26 & 13,0 \\
\hline 33 a 40 anos & 8 & 4,0 \\
\hline \multicolumn{3}{|l|}{ Curso } \\
\hline Enfermagem & 42 & 21,0 \\
\hline Medicina & 120 & 60,0 \\
\hline Odontologia & 38 & 19,0 \\
\hline \multicolumn{3}{|c|}{ Período que está cursando } \\
\hline Desperiodizado & 34 & 17,0 \\
\hline 4은 & 30 & 15,0 \\
\hline 50 & 32 & 16,0 \\
\hline 60 & 23 & 11,5 \\
\hline 70 & 20 & 10,0 \\
\hline 80 & 27 & 13,5 \\
\hline 9음 & 30 & 15,0 \\
\hline $10-12$ 은 & 4 & 2,0 \\
\hline \multicolumn{3}{|l|}{ Procedência } \\
\hline Capital & 96 & 48,0 \\
\hline Interior & 104 & 52,0 \\
\hline
\end{tabular}

Tabela 2. Caracterização dos professores da Escola Superior de Ciências da Saúde participantes da pesquisa (Manaus/AM, 2019)

\begin{tabular}{|c|c|c|}
\hline Características & $\mathrm{n}$ & $\%$ \\
\hline \multicolumn{3}{|l|}{ Sexo } \\
\hline Masculino & 8 & 24,2 \\
\hline Feminino & 25 & 75,8 \\
\hline \multicolumn{3}{|l|}{ Faixa etária } \\
\hline 30 a 41 anos & 14 & 42,4 \\
\hline 42 a 51 anos & 13 & 39,4 \\
\hline 52 a 62 anos & 6 & 18,2 \\
\hline \multicolumn{3}{|l|}{ Curso } \\
\hline Enfermagem & 15 & 45,5 \\
\hline Medicina & 5 & 15,2 \\
\hline Odontologia & 13 & 39,3 \\
\hline \multicolumn{3}{|l|}{ Tempo de formado } \\
\hline Menos de 10 anos & 4 & 12,1 \\
\hline Entre 10 e 20 anos & 15 & 45,5 \\
\hline Entre 21 e 30 anos & 10 & 30,3 \\
\hline Entre 31 e 40 anos & 4 & 12,1 \\
\hline \multicolumn{3}{|c|}{ Formação complementar } \\
\hline Especialização & 4 & 12,1 \\
\hline Mestrado & 6 & 18,2 \\
\hline Doutorado & 22 & 66,7 \\
\hline Pós-doutorado & 1 & 3,0 \\
\hline
\end{tabular}


Em relação às perguntas sobre o tema estudado (Tabela 3), ao questionar se há implicações legais em fotografar ou filmar alguém sem sua prévia autorização e se a imagem da pessoa deve ser preservada, todos os docentes responderam "sim". Já $96,5 \%$ dos discentes disseram "sim" à primeira questão e $98 \%$, à segunda. No que tange aos aspectos legais sobre captação e uso de imagens no Brasil, $101(50,5 \%)$ alunos e 9 (27,3\%) professores desconhecem tais dispositivos na Constituição Federal ${ }^{11} \mathrm{e}$ nos códigos Civil $^{5}$ e Penal ${ }^{12}$ brasileiros. No entanto, $110(55 \%)$ discentes e 25 (75,8\%) docentes afirmaram conhecer, no seu código de ética profissional, a regulamentação específica sobre o tema.

Tabela 3. Conhecimento e prática de discentes e docentes da Escola Superior de Ciências da Saúde quanto ao uso de imagens (Manaus/AM, 2019)

\begin{tabular}{|c|c|c|c|c|c|c|}
\hline & \multirow{2}{*}{ Questão } & \multirow{2}{*}{ Resposta } & \multicolumn{2}{|c|}{ Discentes } & \multicolumn{2}{|c|}{ Docentes } \\
\hline & & & $n$ & $\%$ & $n$ & $\%$ \\
\hline \multirow{12}{*}{ 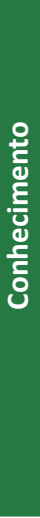 } & \multirow{3}{*}{$\begin{array}{l}\text { Você acha que fotografar ou filmar alguém sem sua } \\
\text { prévia autorização tem implicações legais? }\end{array}$} & Sim & 193 & 96,5 & 33 & 100,0 \\
\hline & & Não & 6 & 3,0 & 0 & 0,0 \\
\hline & & Não sei & 1 & 0,5 & 0 & 0,0 \\
\hline & \multirow{3}{*}{$\begin{array}{l}\text { Você acha que a imagem do indivíduo } \\
\text { deve ser preservada? }\end{array}$} & Sim & 196 & 98,0 & 33 & 100,0 \\
\hline & & Não & 2 & 1,0 & 0 & 0,0 \\
\hline & & Não sei & 2 & 1,0 & 0 & 0,0 \\
\hline & \multirow{3}{*}{$\begin{array}{l}\text { Você conhece, na Constituição Federal, no Código Civil } \\
\text { e no Código Penal brasileiros, algum dispositivo que } \\
\text { disponha sobre a captação e o uso de imagem de pessoas? }\end{array}$} & Sim & 59 & 29,5 & 20 & 60,6 \\
\hline & & Não & 101 & 50,5 & 9 & 27,3 \\
\hline & & Não sei & 40 & 20,0 & 4 & 12,1 \\
\hline & \multirow{3}{*}{$\begin{array}{l}\text { Você conhece, no Código de Ética da sua profissão, } \\
\text { alguma disposição sobre a captação e o uso de imagem } \\
\text { de pacientes? }\end{array}$} & Sim & 110 & 55,0 & 25 & 75,8 \\
\hline & & Não & 56 & 28,0 & 6 & 18,2 \\
\hline & & Não sei & 34 & 17,0 & 2 & 6,0 \\
\hline \multirow{21}{*}{$\frac{2}{8}$} & \multirow{3}{*}{$\begin{array}{l}\text { Você já fotografou algum paciente durante suas } \\
\text { atividades acadêmicas nos serviços de saúde? }\end{array}$} & Sim & 72 & 36,0 & 23 & 69,7 \\
\hline & & Não & 125 & 62,5 & 10 & 30,3 \\
\hline & & Não lembra & 3 & 1,5 & 0 & 0,0 \\
\hline & \multirow{7}{*}{ Se respondeu "sim", com qual finalidade? } & Ensino & 33 & 45,8 & 10 & 43,5 \\
\hline & & Pesquisa & 12 & 16,7 & 1 & 4,4 \\
\hline & & Ensino e pesquisa & 13 & 18,1 & 11 & 47,8 \\
\hline & & Ensino, pesquisa e redes sociais & 5 & 6,9 & 1 & 4,3 \\
\hline & & Ensino e redes sociais & 5 & 6,9 & 0 & 0,0 \\
\hline & & Pesquisa e redes sociais & 2 & 2,8 & 0 & 0,0 \\
\hline & & Redes sociais & 2 & 2,8 & 0 & 0,0 \\
\hline & \multirow{5}{*}{$\begin{array}{l}\text { Quantas vezes você já compartilhou filmagens e/ou } \\
\text { fotografias }\end{array}$} & 1 vez & 29 & 40,3 & 8 & 34,8 \\
\hline & & De 2 a 4 vezes & 13 & 18,1 & 3 & 13,0 \\
\hline & & Mais de 4 vezes & 7 & 9,7 & 5 & 21,7 \\
\hline & & Não lembro & 16 & 22,2 & 6 & 26,1 \\
\hline & & Nunca compartilhei & 7 & 9,7 & 1 & 4,4 \\
\hline & \multirow{6}{*}{$\begin{array}{l}\text { Você pediu autorização verbal e/ou escrita ao paciente } \\
\text { ou seu responsável para fazer essas imagens?* }\end{array}$} & Verbal & 47 & 65,3 & 5 & 15,2 \\
\hline & & Escrita & 16 & 22,2 & 15 & 45,4 \\
\hline & & Não pediu & 5 & 6,9 & 3 & 9,1 \\
\hline & & Em branco & 0 & 0,0 & 10 & 30,3 \\
\hline & & Não lembro & 2 & 2,8 & 0 & 0,0 \\
\hline & & Não houve tempo hábil & 2 & 2,8 & 0 & 0,0 \\
\hline
\end{tabular}

* Admitia-se para esta pergunta que os respondentes assinalassem mais de uma opção.

$\mathrm{Na}$ investigação da prática, ressalta-se que $72(36 \%)$ alunos e $23(69,7 \%)$ professores afirmaram ter fotografado algum paciente durante atividades acadêmicas no serviço de saúde. Dentre as finalidades citadas, o ensino representou $45,8 \%$ das respostas dos discentes e, somado à pesquisa, $47,8 \%$ das respostas dos docentes. Constatou-se ainda o compartilhamento exclusivo em aplicativos e redes sociais, prática declarada por $2,8 \%$ dos estudantes.

Verificou-se também que 42 (58,4\%) discentes e $11(47,8 \%)$ docentes já compartilharam imagens 
de pacientes até quatro vezes. Quanto à forma de autorização para isso, a mais referida entre os alunos foi a verbal $(65,3 \%)$, e entre os docentes, a escrita $(65,2 \%)$ - porém, chama atenção o fato de 10 professores $(43,5 \%)$ não terem respondido a essa questão.

\section{Discussão}

No campo da saúde, é fundamental considerar a produção de conhecimento, a formação profissional e a prestação de serviços como elementos indissociáveis de uma nova prática. As diretrizes curriculares propostas pelo Ministério da Saúde para mudar a formação profissional prevê que a universidade esteja aberta às demandas sociais e seja capaz de produzir conhecimento relevante e útil para a construção do sistema sanitário ${ }^{13}$.

Atualmente, as tecnologias utilizadas pelos profissionais de saúde propiciam novo contexto ético na formação e na prática assistencial. A maioria das pessoas tem telefone celular com câmera fotográfica, facilmente utilizada para registrar em imagens e vídeos situações vivenciadas por pacientes, colegas de trabalho ou na prática acadêmica dentro das instituições de saúde.

Nesse aspecto, os pacientes estão cada vez mais vulneráveis no momento da assistência, principalmente os que apresentam nível de consciência comprometido. Fotografias exibindo lesões cutâneas, fraturas expostas, pessoas acidentadas e óbitos são frequentes em publicações científicas e redes sociais ${ }^{10}$, uso confirmado pelos docentes e discentes.

Entretanto, na maioria das vezes a pessoa que faz esse registro esquece ou desconhece que é imprescindível o consentimento prévio da pessoa envolvida, seja o paciente ou seu responsável, além do profissional encarregado do caso ${ }^{14}$. Os participantes deste estudo já registraram imagens no ambiente assistencial sem solicitar permissão do paciente para isso, mostrando certa frequência dessa prática durante a formação acadêmica.

Apesar disso, a maioria dos participantes demonstrou saber que, atendendo aos preceitos éticos, é preciso obter autorização verbal ou, preferencialmente, escrita para usar informações ou imagens dos pacientes. Ademais, a privacidade do paciente deve ser preservada, e ele não pode ser exposto desnecessariamente, mesmo que o tenha autorizado. Por vezes esse direito é violado, quando se divulgam partes do corpo, imagem radiográfica ou informações do prontuário ${ }^{15}$.
Não se pode proibir o acesso dos profissionais de saúde às imagens dos pacientes, mas seu uso abusivo e contra a vontade dos envolvidos pode incorrer em sanções legais ${ }^{16}$. Em seu artigo 5ㅇ, inciso $X$, a Constituição Federal ${ }^{11}$ menciona a vida privada, a intimidade, a honra e a imagem das pessoas como invioláveis, assegurando o direito da vítima a indenização em caso de transgressão. Ainda assim, revisão integrativa da literatura destacou fragilidades éticas e legais referentes à publicação de imagens de pacientes, sobretudo nos dispositivos brasileiros, quando comparados aos de outros países ${ }^{17}$.

Vale ressaltar que os profissionais de saúde devem ficar atentos aos critérios estabelecidos nos códigos de ética de sua categoria ${ }^{18-20}$.0 Código de Ética dos Profissionais de Enfermagem, no parágrafo único de seu artigo 86 , veta ao enfermeiro fazer referência a casos, situações ou fatos, e inserir imagens que possam identificar pessoas ou instituições sem prévia autorização, em qualquer meio de comunicação ${ }^{18}$. Já o Código de Ética Médica ${ }^{19}$, em seu artigo 75, veda ao profissional publicar ou compartilhar imagens de pacientes; contudo, o Conselho Nacional de Saúde ${ }^{4}$, permite seu uso para fins científicos desde que autorizado em TCLE ou termo de assentimento assinado pelo paciente ou por seu representante legal.

O Código de Ética Odontológica ${ }^{20}$, por sua vez, proíbe ao cirurgião-dentista publicar imagens identificáveis de pacientes, salvo com autorização destes e para fins educativos e de pesquisa. É permitido ao profissional divulgar selfies em que aparece acompanhado de pacientes ou não, bem como imagens do acompanhamento clínico-odontológico, quando for o responsável pelo tratamento, mas isso não descarta a necessidade da autorização prévia em TCLE.

Alguns discentes e docentes conhecem o registro ético para uso de imagens na sua categoria profissional e sabem que, mesmo com consentimento, determinadas situações podem ter repercussão negativa. Martorell, Nascimento e Garrafa ${ }^{6}$ descreveram sentimento contraproducente percebido por profissionais quando confrontados com imagens de pacientes inconscientes feitas em centros cirúrgicos e em atendimentos de urgência, em que não é possível solicitar consentimento prévio.

Além de gerar desconforto com imagens chocantes de situações em que pacientes estão vulneráveis, ao expor esses registros os serviços de saúde ficam fragilizados perante a sociedade, demonstrando falta de sigilo e confiabilidade. Também ferem aspectos relacionados à biossegurança, pois integrantes da equipe assistencial podem contaminar o 
ambiente e mesmo o paciente ao tocá-los depois de manipular o aparelho celular.

Neste sentido, a banalização de informações e registros das rotinas e práticas assistenciais pode se refletir no número de compartilhamentos e comentários decorrentes da divulgação de determinado episódio ${ }^{6}$. Ainda que existam argumentos plausíveis para justificar essa viralização de dados, como a necessidade de esclarecer a população, a exposição de pacientes nas redes sociais precisa ser analisada de forma cautelosa. É sempre prudente que o profissional avalie o contexto ético e legal, bem como as possíveis repercussões desse tipo de divulgação.

\section{Considerações finais}

Este estudo verificou o conhecimento e a prática de discentes e docentes sobre captação e reprodução de imagens de pacientes na prática acadêmica. Os dados mostraram que a maioria dos participantes sabia da legalidade do uso de imagens de pacientes mediante consentimento prévio concedido verbalmente ou por escrito. Os respondentes também mencionaram a existência de legislação específica para isso.

Entretanto, durante a prática docente a solicitação do consentimento do paciente não foi satisfatoriamente empregada nas muitas vezes em que se registraram imagens para atividades de ensino e pesquisa. Preocupa o fato de discentes presenciarem estas condutas, podendo tomá-las equivocadamente como referência ética. Assim, sugere-se reforçar no currículo acadêmico os princípios éticos e legais do uso de imagens para fins de ensino e pesquisa. É preciso destacar as implicações jurídicas dessa prática para o respeito e a privacidade das informações dos pacientes, bem como seu impacto sobre a integridade das instituições de ensino e de saúde.

\section{Referências}

1. Silva ICS, Prates TS, Ribeiro LFS. As novas tecnologias e aprendizagem: desafios enfrentados pelo professor na sala de aula. Debate [Internet]. 2016 [acesso 13 maio 2019];16(15):107-23. DOI: 10.5007/1980-3532.2016n15p107

2. Portugal. Ministério Público. Procuradoria-Geral da República. Convenção para a protecção dos direitos do homem e da dignidade do ser humano face às aplicações da biologia e da medicina: convenção sobre direitos do homem e a biomedicina [Internet]. Lisboa: Ministério Público; 1997 [acesso 22 maio 2019]. Disponível: https://bit.ly/3eVd0S6

3. Organização das Nações Unidas para a Educação, a Ciência e a Cultura. Declaração universal sobre bioética e direitos humanos [Internet]. Paris: Unesco; 2005 [acesso 22 abr 2019]. Disponível: https://bit.ly/2WMLmAm

4. Conselho Nacional de Saúde. Resolução CNS no 510, de 7 de abril de 2016. Dispõe sobre as normas aplicáveis a pesquisas em ciências humanas e sociais cujos procedimentos metodológicos envolvam a utilização de dados diretamente obtidos com os participantes ou de informações identificáveis ou que possam acarretar riscos maiores do que os existentes na vida cotidiana. Diário Oficial da União [Internet]. Brasília, 24 maio 2016 [acesso 15 jun 2020]. Disponível: https://bit.ly/30J7U6t

5. Brasil. Código civil brasileiro e legislação correlata [Internet]. 2a ed. Brasília: Senado Federal; 2008 [acesso 7 maio 2019]. Disponível: https://bit.ly/39mDnPv

6. Martorell LB, Nascimento WF, Garrafa V. Redes sociais, privacidade, confidencialidade e ética: a exposição de imagens de pacientes no Facebook. Interface Comun Saúde Educ [Internet]. 2016 [acesso 22 maio 2019];20(56):13-23. DOI: 10.1590/1807-57622014.0902

7. Marinho LAB, Costa-Gurgel MS, Cecatti JG, Osis MJD. Conhecimento, atitude e prática do autoexame das mamas em centros de saúde. Rev Saúde Pública [Internet]. 2003 [acesso 23 abr 2019];37(5):576-82. DOI: 10.1590/S0034-89102003000500005

8. Leme R. Avaliação de desempenho com foco em competência: a base para remuneração por competências. Rio de Janeiro: Qualitymark; 2006.

9. Conselho Nacional de Saúde. Resolução CNS no 304, de 9 de agosto de 2000. Afirma o respeito devido aos direitos dos povos indígenas no que se refere ao desenvolvimento teórico e prático de pesquisa em seres humanos que envolvam a vida, os territórios, as culturas e os recursos naturais dos povos indígenas do Brasil [Internet]. Brasília, 11 ago 2000 [acesso 23 abr 2019]. Não homologada. Disponível: https://bit.ly/2OP7JRh

10. Caires BR, Lopes MCBT, Okuno MFP, Vancini-Campanharo CR, Batista REA. Conhecimento dos profissionais de saúde sobre os direitos de imagem do paciente. Einstein [Internet]. 2015 [acesso 22 maio 2019];13(2):255-9. DOI: 10.1590/S1679-45082015AO3207

11. Brasil. Constituição da República Federativa do Brasil de 1988. Diário Oficial da União [Internet]. Brasília, 5 out 1988 [acesso 15 jun 2020]. Disponível: https://bit.ly/2Ea68n3

12. Brasil. Decreto-Lei no 2.848, de 7 de dezembro de 1940. Código Penal. Diário Oficial da União [Internet]. Brasília, 31 dez 1940 [acesso 18 ago 2020]. Disponível: https://bit.ly/2E3R1Mj 
13. Feuerwerker LCM. Educação dos profissionais de saúde hoje: problemas, desafios, perspectivas e as propostas do Ministério da Saúde. Rev Abeno [Internet]. 2003 [acesso 3 maio 2019];3(1):24-7. Disponível: https://bit.ly/3jwETDx

14. Batista REA, Campanharo CRV, Cohrs CR. Ética e legalidade na era da imagem digital. Acta Paul Enferm [Internet]. 2012 [acesso 25 jun 2019];25(5):i-ii. DOI: 10.1590/\$0103-21002012000500001

15. Nascimento DB. Análise bioética da utilização de imagens de pacientes em mídias sociais eletrônicas [dissertação] [Internet]. Brasília: Universidade de Brasília; 2016 [acesso 23 maio 2019]. Disponível: https://bit.ly/2Bn3M38

16. Pupulim JSL, Sawada NO. Privacidade física referente à exposição e manipulação corporal: percepção de pacientes hospitalizados. Texto Contexto Enferm [Internet]. 2010 [acesso 23 maio 2019];19(1):36-44. DOI: 10.1590/S0104-07072010000100004

17. Araújo-Passos SM, Santos WM, Silva GLAT, Gonçalves ICM. The ethical and legal aspects of image publications of patients: an integrative literature review. J Psychol Clin Psychiatry [Internet]. 2018 [acesso 19 maio 2019];9(6):705-9. Disponível: https://bit.ly/2BpSmf3

18. Conselho Federal de Enfermagem. Resolução Cofen $n=564$, de 6 de novembro de 2017. Aprova o novo Código de Ética dos Profissionais de Enfermagem. Diário Oficial da União [Internet]. Brasília, 6 dez 2017 [acesso 15 maio 2019]. Disponível: https://bit.ly/2ZSO6Ot

19. Conselho Federal de Medicina. Código de ética médica: Resolução CFM no 2.217, de 27 de setembro de 2018 [Internet]. Brasília: CFM; 2019 [acesso 31 dez 2019]. Disponível: https://bit.ly/3fVHOmT

20. Conselho Federal de Odontologia. Resolução CFO no 118, de 11 de maio de 2012. Revoga o Código de Ética Odontológica aprovado pela Resolução CFO no 42/2003 e aprova outro em substituição. Diário Oficial da União [Internet]. Brasília, 14 jun 2012 [acesso 28 nov 2018]. Disponível: https://bit.ly/3hvYCBn

\section{Participação dos autores}

As autoras elaboraram o trabalho de forma equânime.

\section{Correspondência}

Isabela Cristina de Miranda Gonçalves - Av. Carvalho Leal, 1.777, Cachoeirinha CEP 69065-001. Manaus/AM, Brasil.

Isabela Cristina de Miranda Gonçalves - Doutora - igoncalves@uea.edu.br

(iD) $0000-0002-3868-6226$

Jacqueline de Almeida Gonçalves Sachett - Doutora - jac.sachett@hotmail.com

(iD) 0000-0001-5723-9977

Waldeyde O. Magalhães dos Santos - Doutoranda - waldeydemagalhaes@gmail.com

(iD) 0000-0001-5101-585X

Shirley Maria de Araújo Passos - Doutora - smpassos@uea.edu.br

(iD) $0000-0002-1168-4757$ 